\title{
Theoretical Channels Of International Transmission During The Subprime Crisis To OECD Countries: A FAVAR Model Under Bayesian Framework
}

Olfa KAABIA, University of Paris Ouest Nanterre la Defense, France Ilyes ABID, University of Paris Ouest Nanterre la Defense, France

\begin{abstract}
This paper studies whether and how U.S. shocks are transmitted to other OECD economies in the case of the Subprime Crisis. Using a large data set of 119 major financial and macroeconomic variables in 17 OECD countries from 1980:Q1 to 2006:Q2, we characterize the transmission channels by the interpretable factors and make a structural analysis using FAVAR models under a Bayesian approach.

Our main findings suggest that differences exist in the contagion effects. This implies that no generalizations can be made for OECD countries even of equal economic size and in the same geographic region. Our results show that a large portion of the variance of domestic economic variables is explained by global factors and that the interest rate shock appears to play an important role in the spillover mechanism from the U.S to the OECD countries.
\end{abstract}

Keywords: Transmission Channels; Contagion; Bayesian estimation and FAVAR Models

\section{INTRODUCTION}

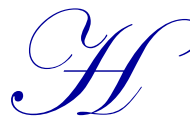

ousing markets are generally viewed as "local" markets, plagued with idiosyncrasies. Nevertheless, there is a large consensus to claim that shock originating from a particular market can easily spread out to other markets in the same segment, or even to other market segments. In fact, the housing price boom during the early 2000s raised questions of possible international transmission of shocks across countries (Otrok and Terrones, 2004).

Moreover, the last housing crisis in USA emerged in the Summer of 2006 was followed by a sharp fall in housing prices in Ireland, New Zealand, Spain and the United Kingdom. These almost parallel developments provide evidence in favor of significant increase in the correlation across national housing markets during the subprime crisis.

The top left graph in Figure 1 illustrates the development of real housing prices for selected countries during 2003-2008. There appears to be a large degree of comovements between very different and distant countries. Graphically it seems that the U.S. housing boom and bust spread to other parts of the world. 


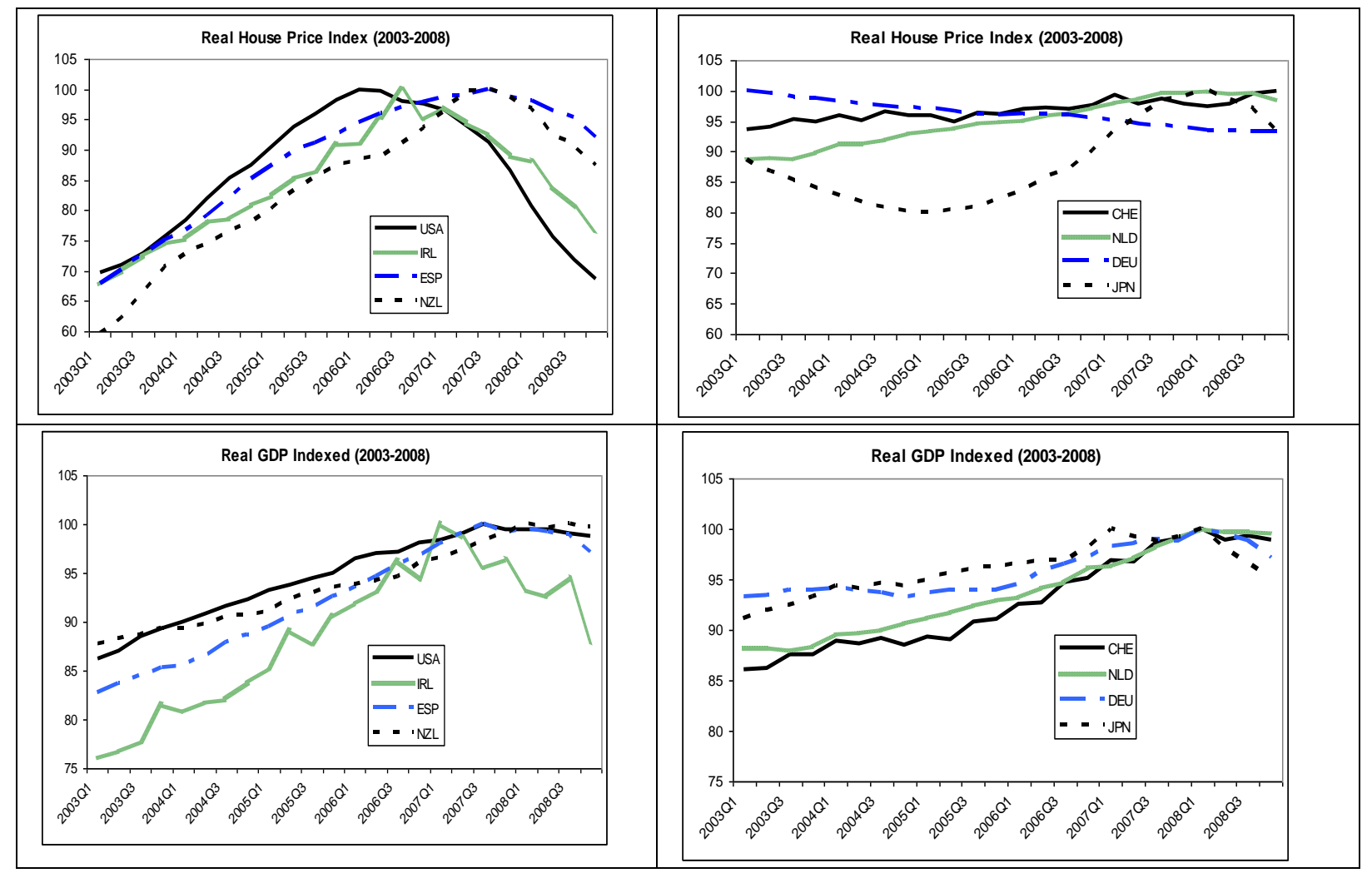

Figure 1: Development of the housing price index and GDP for a selection of countries 2003-2008 (Top panel: real housing price index, bottom panel: real GDP)

Note: The maximum of each variable during 2003-2008 is indexed at 100. The abbreviations IRL, ESP, NZL, CHE, NLD, DEU and JPN denote respectively Ireland, Spain, New-Zealand, Sweden, Netherlands, Germany and Japan.

However, the top right graph in Figure 1 shows that this is not the case for all countries. Germany, the Netherlands and Switzerland seem to be relatively immune to development in U.S. housing market. In contrast to house price developments, GDP growth is severely affected for all eight countries (see bottom panel of Figure 1). To illustrate, Germany and Japan's GDP shrunk stronger than U.S. GDP during 2008. Hence, the exact transmission channel from the U.S. housing market to other countries' real economy is not obvious.

There are several different explanations possible of an international transmission of housing price shocks.

First of all, housing prices may be driven by economic or financial fundamentals (see e.g. Goodhart and Hoffman, 2008). The idea is that housing prices are likely to comove if housing prices are driven by fundamentals and if the cycles of fundamentals are correlated. For example, an increase in U.S. interest rates increases global interest rates, which increases the cost of borrowing across countries. Hence, home buyers are credit constrained, which affects directly house prices.

Second, due to the wealth effect a decrease in house prices will induce households to reduce their consumption (see e.g. Lettau and Ludvigson, 2004 and Case et al., 2005). Since households consume both domestic and foreign goods and services, these effects reduce demand for other countries' export sectors.

Third, news on housing prices in some countries may lead investors and (potential) house buyers to revise their expectations on housing prices in other countries. For instance, these revised expectations can be unrelated to changes in fundamentals akin to contagion effects in exchange rates and stock markets during the Asian crisis (Kaminsky and Reinhart, 2000). Hence, there are complex international links between housing markets and the real 
economy. In this paper, we aim at going further beyond questions of international transmission of housing prices in normal period to examine "contagion effects" during the turmoil event of the subprime crisis.

The scope of this study is to contribute to the literature on international transmission of U.S. shocks by exploring the transmission channels process and contagion effects during the subprime crisis. By contagion we mean, as in the case of a pandemic, a process where a sudden change in local prices in one country affects global prices, which in turn influence local prices in other countries. In fact, the contagion is detected in the case that an unanticipated shock appears suddenly in a country and thereof creates a significant increasing (or decreasing) in the comovements between variables.

This paper investigates the two principal questions: Is there evidence of contagion effects on the OECD countries during the subprime crisis? And what are the important channels through which U.S. shocks are transmitted to the considered OECD economies?

To answer these questions, we will measure the international comovements employing a dynamic Bayesian FAVAR approach. The motivation is to identify a few common factors that capture common fluctuations in large multi-dimensional datasets. We follow Stock and Watson (2003), Bai (2003), Bernanke et al. (2005) and Bai and Ng (2008) dealing with large systems. But as VARs suffer from dimensionality problems when the number of variables increases, it is not possible to include a large set of variables. The common idea of FAVAR models is that the extracted factors summarize common information in variables to reduce the size of the VAR to allow a more efficient estimation, while still incorporating as much information from variables as possible. However, in all the existing studies in the literature ${ }^{1}$, those extracted factors are not interpretable. So, one of the originality of our work is to deal with constrained factors by introducing a Bayesian approach so as to identify and interpret the transmission channels. In fact, it is worth emphasizing that there are many methods to extract factors; here we choose to estimate constrained factors from a large database so as to interpret them as global, country-specific and variable-type factors. This way, we want to give a precise characterization of the transmission channels in the contagion processes during the housing crisis in USA in 2006. So, the novelty of our FAVAR approach comparing to the one of Bernanke, Boivin and Eliasz (2005) is in the way of extracting the factors.

Our approach differs from the one of Iacoviello and Neri (2010), where they aimed to structurally model the different sources of shocks, including crisis, technology shocks, monetary policy shocks, etc... In this paper we rather focus on short run links across markets, in order to investigate what happened in the recent subprime crisis, which spread out to the world economy.

Our sample consists of 17 OECD countries with quarterly data from 1980:Q1 until 2006:Q2 so as to stop before the outbreak of the subprime crisis. It is worth emphasizing that this sample is larger than related studies by e.g. Otrok and Terrones (2004) and Beltratti and Morana (2010). For instance, the latter authors consider only the G7 and treat the European Monetary Union as one country. Two specific American shocks are studied. First, a shock in housing prices and second a shock in short-term interest rates. We consider the subprime crisis and study how these shocks affect the considered OECD economies.

Our results show that a large portion of the variance of domestic OECD economic and financial variables is explained by the common factors. However, there are important differences between the OECD countries. This suggests that American shocks, which are able to impact the global factors, will be transmitted to some, but not all OECD countries. More precisely, Australia, the United Kingdom and Scandinavian countries appear to be most sensitive to global shocks. However, even though global developments play an important role in most OECD economies, a large part of the variance is still idiosyncratic.

The plan of the paper is the following. Section 2 recalls the main principles of the econometric methodology we retain to investigate the question of contagion, the Bayesian FAVAR model. Section 3 presents the data, summarizes the findings and Section 4 concludes.

\footnotetext{
${ }^{1}$ See for example, Bai (2003), Stock and Watson (2003, 2005), Bernanke et al. (2005).
} 


\section{METHODOLOGY}

We recall the main points in the econometric modeling adopted to estimate FAVAR models under a Bayesian approach. Although the VAR approach has been extensively employed in studying contagion effects, different criticisms have been directed at the sparse information content of VAR models. A typical VAR model for an international contagion study does not usually include more than eight variables because of the degrees of freedom restriction which could not accurately reflect the necessary information. Moreover, a VAR model may exclude variables that may be relevant in that transmission process.

To overcome the shortcomings of VAR models, a new methodology has been proposed by Bernanke and al. (2005), a FAVAR model. This methodology consists of two basic equations in a two-step procedure similar to that of Stock and Watson $(2003,2005)$. Here, we follow Bernanke et al. (2005). However, our novelty comparing to the previous authors is the inclusion of constrained factors. We assume that dealing with interpretable factors allows a clearer identification of international transmission mechanisms compared to alternatives using principal components. ${ }^{2}$ This will benefit the economic interpretation of our results.

The idea underlying the FAVAR models estimated by Bernanke et al. (2005) is the following: if a small number of estimated factors effectively summarize large amounts of information about the economy, then a natural solution to the degrees-of-freedom problem in VAR analyses - which have to be of limited dimensions - is to augment standard VARs with estimated factors.

Accordingly, one considers a $(\mathrm{M} \times 1)$ vector $Y_{t}$ of observable economic variables of interest. One assumes that additional economic information, not fully captured by the $Y_{t}$ series, may also be relevant to modeling the dynamics of these series. More precisely, this additional information can be summarized by an $(K \times 1)$ vector of unobserved factors, $F_{t}$, where $\mathrm{K}$ is "small". The joint dynamics of $\left(Y_{t}, F_{t}\right)$ are given by:

$\left[\begin{array}{l}F_{t} \\ Y_{t}\end{array}\right]=\Phi(L)\left[\begin{array}{l}F_{t-1} \\ Y_{t-1}\end{array}\right]+\xi_{t}$

with $\xi_{t}$ denoting a white noise process.

The FAVAR model cannot be estimated directly because the factors $F_{t}$ are unobservable. However, as the factors represent forces that potentially affect many economic variables, Bernanke et al. suppose that it is possible to infer something about the factors from observations on a variety of economic "informational" time series, denoted by a $(\mathrm{N} \times 1)$ vector $X_{t}$. The number of informational time series $\mathrm{N}$ is "large", generally assumed to be much greater than the number of factors. The series $X_{t}$ is related to the unobservable factors $F_{t}$ and the observable factors $Y_{t}$ as follows:

$X_{t}=\lambda^{f} F_{t}+\lambda^{y} Y_{t}+e_{t}$

where $\lambda^{f}$ is an $(\mathrm{N} \times \mathrm{K})$ matrix of factor loadings, $\lambda^{y}$ is $(\mathrm{N} \times \mathrm{M})$ matrix, and $e_{t}$, is the $(\mathrm{N} \times 1)$ vector of the error terms, which are mean zero and assumed as either weakly correlated, or uncorrelated, depending on whether estimation is obtained by principal components, or likelihood methods because, according to Bernanke et al., the model can be estimated in those two ways.

In our case, we adopt the two-step procedure, but, at the first stage, we estimate the constrained factors by using a Bayesian estimation method. First, to identify unobservable forces (factors), we use a dynamic factor model originally introduced by Otrok and Whiteman (1998) and further developed by Kose et al. (2005) and Del Negro

\footnotetext{
${ }^{2}$ See Eickmeier (2007) for instance.
} 
and Otrok (2007). The factor structure itself is directly motivated by general equilibrium models as shown in Altug (1989) and Sargent (1989).

For each country $i$, we consider a set of economic and financial variables $\left(X_{i, j, t}\right), 1 \leq \mathrm{j} \leq \mathrm{J}$. We assume that these variables obey a factor model as follows:

$$
X_{i, j, t}=\lambda_{i, j}{ }^{(G)} F_{t}^{(G)}+\sum_{v=1}^{V} \lambda_{i, j}{ }^{(v)} F_{t}^{(v)}+\sum_{c=1}^{C} \lambda_{i, j}{ }^{(c)} F_{t}^{(c)}+\varepsilon_{i, j, t}
$$

where $F^{(G)}$ denotes a global factor, $F^{(c)}$ a factor specific for country c and $F^{(v)}$ a factor representative of a type of variable $\mathrm{v}$.

For clearness, the dynamic factor model used in this paper assumes that housing prices and the other macroeconomic and financial variables, can be explained by the following three types of factors: the global factor or world one, the country-specific factors and the variable-type factors.

The idiosyncratic errors $\varepsilon_{i, j, t}$ are serially correlated, and are modeled as $p$-order autoregressions.

$$
\varepsilon_{i, j, t}=\phi_{i, j, 1} \varepsilon_{i, j, t-1}+\phi_{i, j, 2} \varepsilon_{i, j, t-2}+\ldots+\phi_{i, j, p} \varepsilon_{i, j, t-p}+u_{i, j, t}
$$

Also, we suppose that: $\left\{\begin{array}{l}E\left(\varepsilon_{i, j, t}, \varepsilon_{i^{\prime}, j^{\prime}, s}\right)=0 \text { for }(i, j) \neq\left(i^{\prime}, j^{\prime}\right) \text { and } t \neq s \\ E\left(\varepsilon_{i, j, t}, \varepsilon_{i^{\prime}, j^{\prime}, s}\right)=\sigma_{i, j}^{2} \text { otherwise }\end{array}\right.$

Each factor $F_{t}$ is dynamic and obeying an autoregressive model of order $q^{(F)}$ as follows:

$$
F_{t}^{(F)}=\varphi_{0,1}^{(F)} F_{t-1}^{(F)}+\varphi_{0,2}^{(F)} F_{t-2}^{(F)}+\ldots+\varphi_{0, q}^{(F)} F_{t-q}^{(F)}+v_{0, t}^{(F)} ; F=G, \text { vor } c
$$

If the dynamic factors were observable, the estimation of the equations (3)-(4) would be straightforward. Since it is not, special methods must be employed as is done in the literature. Stock and Watson $(2003,2005)$ treat the model as an observer system and employ Kalman filter to estimate the model parameters and extract an estimate of the unobserved factors. In our analysis, we choose an alternative procedure based on a recent development in the Bayesian literature on, that of " data augmentation"..

Also, as to give an interpretation to the different factors (world, country-specific, and variable-type factors), we identify them by making two sign restrictions because neither the signs nor the scales of the factors and the factor loadings are separately identified.

Signs are identified by requiring one of the factor loadings, $\lambda_{i, j}$, to be positive for each of the factors. In practice, the factor loading for the world factor is imposed to be positive for the U.S. GDP. In this sense, country factors are identified by positive factor loadings for GDP for each country. The specific-type factors are identified by positive loadings for the U.S variables listed for each specific factor.

Then the scales are identified, following Sargent and Sims (1977) and Stock and Watson (2003, 2005), by assuming that each factor variance, $\sigma_{F^{(F)}}^{2}$, is equal to a constant. If we denote by $\theta$ the set of unknown parameters $\left(\lambda_{i, j}, \sigma_{i, j}^{2}, \phi_{i, j, t-p}, \varphi_{0, q}^{(F)}, \sigma_{F^{(F)}}^{2}\right)$, the idea is given a prior of the factors, one determine posterior distributions for all unknown parameters conditional on the latent factors, noted $p\left(\theta \mid F^{(F)}\right)$. And then determine the conditional distribution of the latent factors given the observables and the other parameters, noted $p\left(F^{(F)} \mid \theta\right)$. So the joint

\footnotetext{
${ }^{3}$ See Tanner and Wong (1987) for more details on missing data problems.
} 
posterior distribution for the unknown parameters and the unobserved factors can be sampled by using a Markov Chain Monte Carlo procedure on the full set of conditional distributions. In other words, we will generate a Markov chain whose stationary distribution is the distribution of interest ${ }^{4}$.

Then once the factors extracted and at the second stage, a FAVAR model is estimated. It is worth noticing that the Bayesian method provides a tightly estimation of the factors at the first step and so, the uncertainty in the estimated factors is negligible (Kose et al. 2003) allowing to estimate the FAVAR model like a standard VAR model as Bernanke et al. do. Moreover, to account for the uncertainty in the factor estimation, we implement a bootstrap procedure, in order to obtain accurate confidence intervals on the impulse response functions deduced from the FAVARs.

Our interest is to investigate contagion effects on $X_{t}$ by assuming an initial positive shock on $Y_{t}$ which spreads through the extracted factors $F_{t}$. According to that, we put in the FAVAR models two factors in addition to a key observable variable, $Y_{t}$, on which we simulate an initial shock. Then, we study the effects on the informational time series $X_{t}$. This captures the idea that both $Y_{t}$ and $F_{t}$ represent pervasive forces that drive the common dynamics of $X_{t}$. Let us note that in our analysis, the innovations of the FAVAR models are orthogonalized according to a Cholesky ordering as it is the common practice in previous studies. ${ }^{5}$ If one can get empirical evidence of a significant dynamic transmission of a local shock (originating from a local market or country) to a particular common factor, one can derive the dynamic responses of the other markets as transmitted by a factor. Such responses are pandemic as much as they simultaneously affect all markets whose dynamics are significantly explained by the factor. Once the different constrained factors are extracted, they are included in a FAVAR model, alongside an observable indicator Y associated with the local shock under study. For example, we include the American housing price growth rate in the FAVAR model if we aim at investigating the impact of a shock originating from the American housing market. Next, by inverting the chosen FAVAR model $\left(F_{1}, F_{2}, \ldots, Y_{j}\right)$ we can obtain the impulse responses $\operatorname{IR}\left(F_{1}, \varepsilon_{Y_{j}}, h\right), \operatorname{IR}\left(F_{2}, \varepsilon_{Y_{j}}, h\right), \ldots$ of the different factors $\left(F_{1}, F_{2}, \ldots\right)$ to a shock to $Y_{j}$.

If one gets empirical evidence in favor of significant responses for a significant number of countries, one can conclude that there may be contagion effects, as the local shock spreads out through factors to a large number of countries at the same time.

\section{EMPIRICAL FRAMEWORK}

\subsection{Data}

Our dataset is primarily drawn from Banque de France and Global Financial Data. It includes quarterly data from 1980:Q1 to 2006:Q2 for 17 OECD countries :United States (US), Canada (CAN), Finland (FIN), France (FRA), Germany (DEU), Ireland (IRL), Italy (ITA), Netherlands (NLD), Spain (ESP), Denmark (DNK), Norway (NOR), Sweden (CHE), Switzerland (SWI), United Kingdom (UK), Australia (AUS), Japan (JPN) and NewZealand (NZL).

Seven economic variables are included par country in the sample: GDP, Consumption, Investment, Housing Price Index, Short Run Interest Rate (3-month), Long Run Interest Rate (10-year) and Stock Market Index. Except for the interest rates (IRS and IRL), all variables are taken in real terms (taken as nominal and divided by the Consumer Price Index) so as to take into account the inflation.

All the data is seasonally adjusted and the variables are measured at constant national prices. As is usually done in the literature, interest rates are differenced and activity variables are logarithmized. We compute the growth

\footnotetext{
${ }^{4}$ For more details concerning the implemented algorithm, see Otrok and Whiteman (1998).

${ }^{5}$ Cf. Stock and Watson (2005) and Bernanke and al. (2005). 
rates and remove the mean from each series. Growth rates are used because we aim to investigate the short run effects and not long run effects of shocks in the FAVAR.

The subprime crisis may represent a break in the dynamic relationships between variables and factors so for that we stop before it and it is not accounted in our sample.

\subsection{Results}

In our analysis and according to the equation (3), we consider for each of the seventeen OECD country, a set of seven economic and financial variables, $1 \leq \mathrm{j} \leq 7$, namely, GDP, consumption, investment, interest rates (long and short), stock index returns and housing price index returns. Also, we took $\mathrm{V}=4 ; \mathrm{C}=17$ and $p=q^{(F)}=4$.

We assume that housing prices and the other macroeconomic and financial variables, can be explained by the following three types of factors:

- The Global factor or World factor captures the common shocks affecting all the variables.

- A Country-specific factor, which captures common shocks to variables in a country.

- A Variable-type factor, which captures common shocks affecting a type of variable in all the countries but not for other variables. We distinguish four types of variable specific factors. First, the real factor (or real activity factor) captures comovements among GDP, consumption and investment. Second, the interest factor captures comovements for short run and long run interest rates. Third, the stock factor captures comovements among stock markets and fourth, the housing factor is the common factor for all domestic housing series. So using this set-up the total number of factors extracted from the 119 series is $\mathrm{K}=22$ $(1+17+4)$.

\subsubsection{The Transmission Channels Analysis}

So as to better characterize the transmission channels in the case of studying contagion effects during the subprime crisis, we propose to start by analyzing the dynamic extracted factors.

We examine the evolution of the different factors and analyze their ability to track important events or business cycle episodes since 1980 by analyzing the factors' graphs reported in the appendix.

Unlike previous authors like Stock and Watson (2005) and Bernanke et al. (2005), we trace the factors and study the precision with which the factors where extracted.

Figure 2 displays the posterior median of the global factor along with the $10 \%$ and $90 \%$ quantiles. The tight confidence bounds indicate the precision with which the factor is extracted. This precision is important when including the factor as observable in the FAVAR.

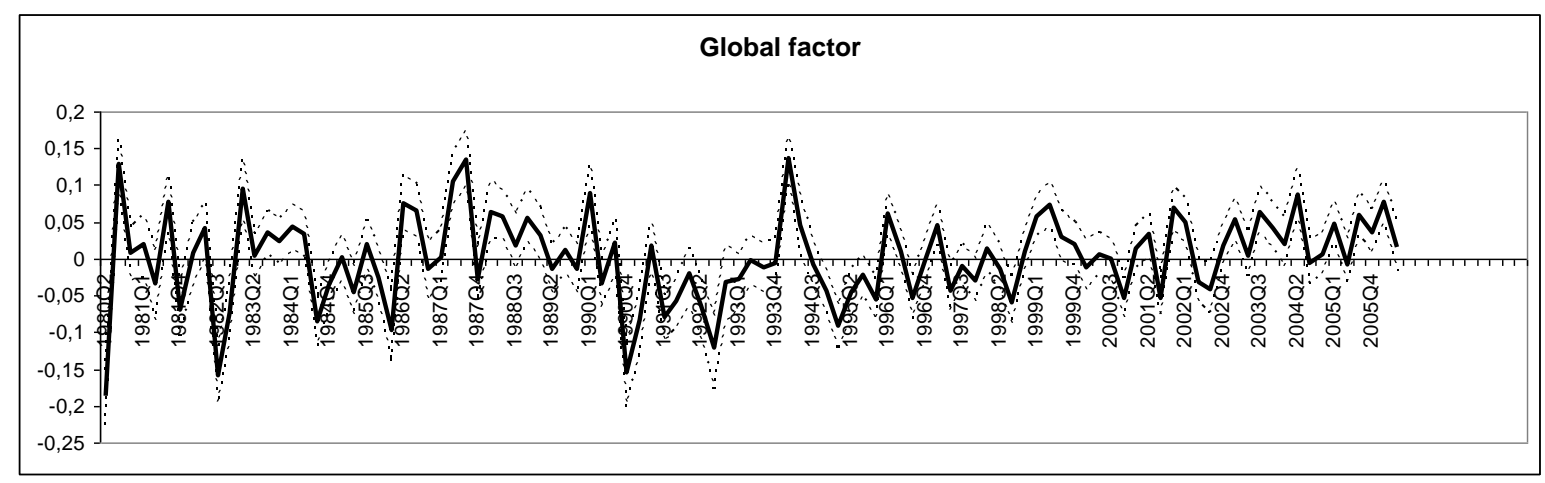

Figure 2: Posterior median, $10 \%$ and $90 \%$ quantiles of the global factor. 
The global factor summarizes the common behavior of all 119 series in the database. This factor is clearly time-varying and provides a general indication of the state of the world economy. The recessions of the early 1980s and early 1990s are clearly visible. However, for a better understanding on the specific development of economic variables we need to consider the variable-type factors too.
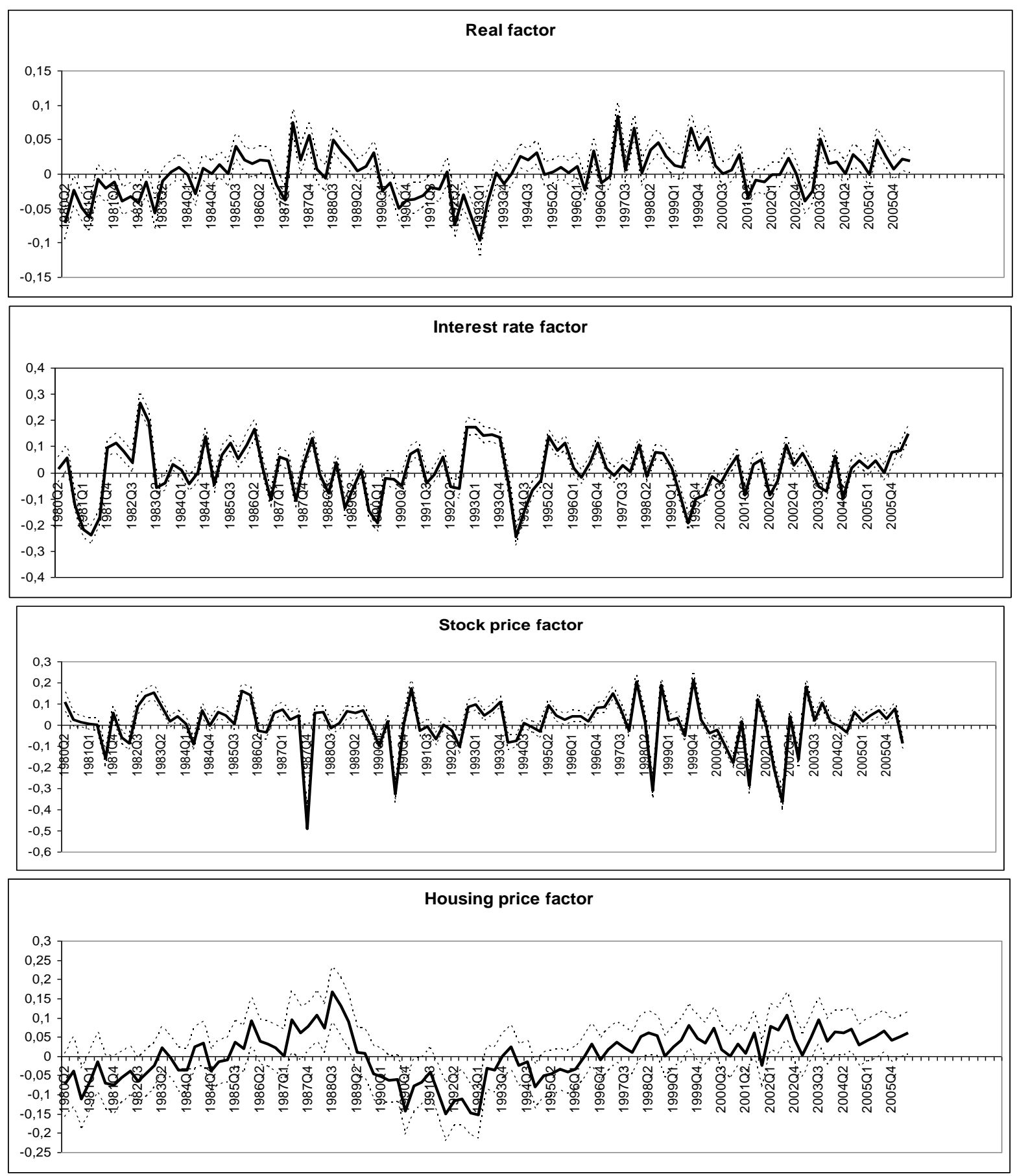

Figure 3: Posterior median, $10 \%$ and $90 \%$ quantiles of the variable-type factors (from top to bottom panel: Real factor, Interest Rate factor, Stock Market factor and Housing Price factor) 
The variable-specific factors are presented in Figure 3. From top to bottom, the graphs represent the real factor, the interest rate factor, the stock market factor and the house price factor. We notice the tight confidence bounds around the factors, with the only exception being the house price factor, which has wider confidence bounds.

Let us first consider the housing factor which reflects the main developments in global housing markets. It is worth noting that it accounts for the housing price bust of the early 1980s and the housing price boom of the late 1980s. In the beginning of the 1990s the economic recessions resulted in a slump in house prices, which started to stabilize in the mid 1990s. The house price boom of the late 1990s and early 2000s is clearly captured.

However, it is important to keep in mind that the confidence bounds are relatively large, indicating that there is not one single global house price factor, but that there important differences between countries' housing markets : i.e, Giuliodori (2005) shows the importance of institutional difference for monetary policy transmission across European countries.

Second, the real factor summarizes the information contained in all countries' GDP, consumption and investment series. This factor captures the recessions of the early 1980s and early 1990s quite well.

Moreover, common variations in the two interest rate series are captured by the interest rate factor. This factor also captures several important events. The ERM crisis of 1992-1994 is clearly captured, with first increasing interest rates, followed by decreasing ones. During 1999-2000 interest rates were very low and increased after the burst of the Dot-com bubble. We remark clearly the increase in the interest rates. This maybe a consequence of the increase in the Fed funds rate in 2005.

Also as expected, the stock factor captures the past declines in the stock markets, such as the 1987 crash and also the long boom of the 1990s. Comparing to the other type-variable factors, this factor appears to be more volatile. However, note that the confidence bounds are very tight, indicating a large degree of synchronization across national stock market indexes.

Next, we will use variance decompositions to measure the relative contributions of the global factor, the variable-type and country-specific factors to business cycle fluctuations in each country. The variance decomposition analysis is crucial in such contagion studies. In fact, if we found in the subprime crisis that the variance part is significantly more pronounced, we found evidence of contagion effects.

\subsubsection{The Variance Decompositions}

The graphical investigation of the factors is complemented by the variance decompositions of the explained factors to assess how important each factor is for each variable. Such decompositions provide indications about how country's fluctuations are associated with global fluctuations and variable type.

The variance decompositions reported in Table 1 show the percentage of the variation in each series explained by the global factor, the type factors (real, interest, stock, housing) and country factors.

We are interested on what is explained by the fundamental so the part of the variance not explained by these factors is idiosyncratic. For each variable we will discuss in turn the importance of common factors.

However, in order to avoid spurious correlation, the common factor that we used in the variance decompositions for a given variable is computed from a database that excludes that variable. For instance, in the case of getting the variance decomposition of the world factor in the American consumption, we exclude that last variable. 
Table 1: Variance Decompositions

\begin{tabular}{|c|c|c|c|c|c|c|c|c|c|c|c|c|c|c|c|c|c|}
\hline Factor & USA & CAN & FIN & FRA & DEU & IRL & ITA & NLD & ESP & DNK & NOR & SWE & CHE & GBR & AUS & JPN & NZL \\
\hline \multicolumn{18}{|c|}{ Gross Domestic Product } \\
\hline World & $17 \%$ & $19 \%$ & $8 \%$ & $6 \%$ & $1 \%$ & $1 \%$ & $2 \%$ & $2 \%$ & $6 \%$ & $0 \%$ & $0 \%$ & $8 \%$ & $5 \%$ & $20 \%$ & $9 \%$ & $5 \%$ & $0 \%$ \\
\hline Country & $4 \%$ & $11 \%$ & $16 \%$ & $43 \%$ & $10 \%$ & $18 \%$ & $22 \%$ & $10 \%$ & $18 \%$ & $15 \%$ & $8 \%$ & $30 \%$ & $16 \%$ & $13 \%$ & $11 \%$ & $1 \%$ & $5 \%$ \\
\hline Real activity & $40 \%$ & $27 \%$ & $32 \%$ & $2 \%$ & $57 \%$ & $42 \%$ & $3 \%$ & $41 \%$ & $21 \%$ & $7 \%$ & $3 \%$ & $0 \%$ & $27 \%$ & $9 \%$ & $4 \%$ & $61 \%$ & $20 \%$ \\
\hline idiosyncratic & $39 \%$ & $43 \%$ & $44 \%$ & $49 \%$ & $32 \%$ & $39 \%$ & $72 \%$ & $47 \%$ & $54 \%$ & $78 \%$ & $89 \%$ & $61 \%$ & $51 \%$ & $57 \%$ & $76 \%$ & $32 \%$ & $74 \%$ \\
\hline \multicolumn{18}{|c|}{ Consumption } \\
\hline World & $21 \%$ & $22 \%$ & $0 \%$ & $3 \%$ & $0 \%$ & $2 \%$ & $3 \%$ & $0 \%$ & $9 \%$ & $1 \%$ & $0 \%$ & $3 \%$ & $3 \%$ & $8 \%$ & $9 \%$ & $2 \%$ & $8 \%$ \\
\hline Country & $10 \%$ & $9 \%$ & $19 \%$ & $22 \%$ & $3 \%$ & $21 \%$ & $21 \%$ & $11 \%$ & $31 \%$ & $18 \%$ & $7 \%$ & $27 \%$ & $10 \%$ & $16 \%$ & $10 \%$ & $0 \%$ & $2 \%$ \\
\hline Real activity & $21 \%$ & $20 \%$ & $25 \%$ & $1 \%$ & $34 \%$ & $11 \%$ & $0 \%$ & $17 \%$ & $9 \%$ & $6 \%$ & $4 \%$ & $0 \%$ & $24 \%$ & $12 \%$ & $12 \%$ & $43 \%$ & $25 \%$ \\
\hline idiosyncratic & $48 \%$ & $49 \%$ & $55 \%$ & $74 \%$ & $62 \%$ & $65 \%$ & $75 \%$ & $71 \%$ & $50 \%$ & $73 \%$ & $88 \%$ & $69 \%$ & $63 \%$ & $63 \%$ & $70 \%$ & $54 \%$ & $65 \%$ \\
\hline \multicolumn{18}{|c|}{ Investment } \\
\hline World & $13 \%$ & $12 \%$ & $2 \%$ & $11 \%$ & $0 \%$ & $4 \%$ & $3 \%$ & $7 \%$ & $0 \%$ & $0 \%$ & $0 \%$ & $5 \%$ & $13 \%$ & $7 \%$ & $6 \%$ & $3 \%$ & $1 \%$ \\
\hline Country & $6 \%$ & $14 \%$ & $9 \%$ & $35 \%$ & $7 \%$ & $18 \%$ & $29 \%$ & $4 \%$ & $23 \%$ & $5 \%$ & $1 \%$ & $16 \%$ & $8 \%$ & $17 \%$ & $5 \%$ & $3 \%$ & $1 \%$ \\
\hline Real activity & $51 \%$ & $19 \%$ & $30 \%$ & $0 \%$ & $43 \%$ & $40 \%$ & $3 \%$ & $24 \%$ & $1 \%$ & $0 \%$ & $1 \%$ & $0 \%$ & $10 \%$ & $2 \%$ & $6 \%$ & $53 \%$ & $18 \%$ \\
\hline idiosyncratic & $29 \%$ & $55 \%$ & $59 \%$ & $53 \%$ & $49 \%$ & $37 \%$ & $64 \%$ & $65 \%$ & $74 \%$ & $94 \%$ & $97 \%$ & $78 \%$ & $68 \%$ & $73 \%$ & $82 \%$ & $40 \%$ & $79 \%$ \\
\hline \multicolumn{18}{|c|}{ 3-Month Short Interest Rate } \\
\hline World & $5 \%$ & $1 \%$ & $0 \%$ & $0 \%$ & $1 \%$ & $1 \%$ & $5 \%$ & $0 \%$ & $1 \%$ & $0 \%$ & $2 \%$ & $0 \%$ & $0 \%$ & $0 \%$ & $0 \%$ & $2 \%$ & $0 \%$ \\
\hline Country & $12 \%$ & $23 \%$ & $3 \%$ & $19 \%$ & $38 \%$ & $4 \%$ & $17 \%$ & $41 \%$ & $2 \%$ & $2 \%$ & $4 \%$ & $17 \%$ & $28 \%$ & $8 \%$ & $5 \%$ & $2 \%$ & $41 \%$ \\
\hline Interest & $16 \%$ & $1 \%$ & $5 \%$ & $3 \%$ & $2 \%$ & $0 \%$ & $8 \%$ & $3 \%$ & $4 \%$ & $7 \%$ & $9 \%$ & $11 \%$ & $11 \%$ & $2 \%$ & $37 \%$ & $1 \%$ & $0 \%$ \\
\hline idiosyncratic & $67 \%$ & $74 \%$ & $92 \%$ & $77 \%$ & $58 \%$ & $95 \%$ & $70 \%$ & $55 \%$ & $93 \%$ & $91 \%$ & $84 \%$ & $72 \%$ & $60 \%$ & $89 \%$ & $57 \%$ & $94 \%$ & $58 \%$ \\
\hline \multicolumn{18}{|c|}{ 10-Year Long Interest Rate } \\
\hline World & $24 \%$ & $12 \%$ & $2 \%$ & $2 \%$ & $3 \%$ & $2 \%$ & $0 \%$ & $3 \%$ & $1 \%$ & $3 \%$ & $0 \%$ & $9 \%$ & $8 \%$ & $9 \%$ & $4 \%$ & $9 \%$ & $0 \%$ \\
\hline Country & $29 \%$ & $36 \%$ & $32 \%$ & $64 \%$ & $73 \%$ & $38 \%$ & $36 \%$ & $78 \%$ & $17 \%$ & $22 \%$ & $26 \%$ & $31 \%$ & $51 \%$ & $37 \%$ & $27 \%$ & $21 \%$ & $4 \%$ \\
\hline Interest & $6 \%$ & $5 \%$ & $5 \%$ & $15 \%$ & $0 \%$ & $0 \%$ & $21 \%$ & $2 \%$ & $6 \%$ & $47 \%$ & $23 \%$ & $46 \%$ & $14 \%$ & $8 \%$ & $37 \%$ & $0 \%$ & $1 \%$ \\
\hline idiosyn & $40 \%$ & $47 \%$ & $60 \%$ & $19 \%$ & $23 \%$ & $60 \%$ & $42 \%$ & $15 \%$ & $75 \%$ & $27 \%$ & $50 \%$ & $14 \%$ & $27 \%$ & $46 \%$ & $32 \%$ & $69 \%$ & $93 \%$ \\
\hline \multicolumn{18}{|c|}{ Stock Market Index } \\
\hline World & $0 \%$ & $1 \%$ & $8 \%$ & $3 \%$ & $4 \%$ & $6 \%$ & $4 \%$ & $3 \%$ & $2 \%$ & $9 \%$ & $16 \%$ & $3 \%$ & $1 \%$ & $0 \%$ & $2 \%$ & $5 \%$ & $2 \%$ \\
\hline Country & $79 \%$ & $65 \%$ & $45 \%$ & $66 \%$ & $73 \%$ & $60 \%$ & $50 \%$ & $82 \%$ & $53 \%$ & $46 \%$ & $51 \%$ & $69 \%$ & $77 \%$ & $78 \%$ & $50 \%$ & $34 \%$ & $35 \%$ \\
\hline Stock & $0 \%$ & $11 \%$ & $0 \%$ & $16 \%$ & $0 \%$ & $1 \%$ & $0 \%$ & $0 \%$ & $1 \%$ & $4 \%$ & $10 \%$ & $5 \%$ & $0 \%$ & $4 \%$ & $1 \%$ & $1 \%$ & $1 \%$ \\
\hline idiosyncratic & $21 \%$ & $23 \%$ & $47 \%$ & $15 \%$ & $22 \%$ & $31 \%$ & $45 \%$ & $15 \%$ & $42 \%$ & $41 \%$ & $23 \%$ & $23 \%$ & $22 \%$ & $18 \%$ & $46 \%$ & $60 \%$ & $62 \%$ \\
\hline \multicolumn{18}{|c|}{ Housing Prices Index } \\
\hline World & $12 \%$ & $12 \%$ & $14 \%$ & $3 \%$ & $0 \%$ & $5 \%$ & $0 \%$ & $0 \%$ & $12 \%$ & $1 \%$ & $3 \%$ & $6 \%$ & $6 \%$ & $10 \%$ & $4 \%$ & $9 \%$ & $13 \%$ \\
\hline Country & $24 \%$ & $8 \%$ & $22 \%$ & $3 \%$ & $0 \%$ & $5 \%$ & $1 \%$ & $6 \%$ & $22 \%$ & $6 \%$ & $10 \%$ & $35 \%$ & $16 \%$ & $35 \%$ & $17 \%$ & $7 \%$ & $2 \%$ \\
\hline Housing & $2 \%$ & $9 \%$ & $24 \%$ & $1 \%$ & $19 \%$ & $24 \%$ & $3 \%$ & $22 \%$ & $14 \%$ & $14 \%$ & $1 \%$ & $0 \%$ & $2 \%$ & $4 \%$ & $2 \%$ & $18 \%$ & $16 \%$ \\
\hline idiosyncratic & $59 \%$ & $71 \%$ & $38 \%$ & $92 \%$ & $79 \%$ & $66 \%$ & $95 \%$ & $70 \%$ & $51 \%$ & $78 \%$ & $85 \%$ & $58 \%$ & $73 \%$ & $48 \%$ & $76 \%$ & $64 \%$ & $68 \%$ \\
\hline
\end{tabular}

Note: The table reports the median percentage of the variance decomposition.

First, the country factor is an important determinant of GDP in many countries. For about half of the countries more than $25 \%$ percent is explained by the country factor. However, global developments captured by the global and real factors are important as well. For most countries over $20 \%$ of the variation in GDP is explained by global factors. However, in some countries, such as Norway, GDP growth behaves rather idiosyncratially and global developments do not seem to matter as much as for other countries, e.g. France, Italy and Spain. Consumption and investment show a rather similar picture as GDP, where investment seems to be even more independent from international events. For example, in Denmark and Sweden over $90 \%$ of the explained variance in investment is idiosyncratic.

Second, turning to the four interest rate related variables, there is quite some variety in the variance explained by the common factors.

The interest rate factor explains much cross-country variation in short run and long run interest rates. For example, the interest rate factor explains over $70 \%$ of the movements in long term interest rates in Germany and the Netherlands. In fact, only in New Zealand this factor has low explanatory power. In fact, the global interest rate and country factors do not explain more than $25 \%$ in any country. In addition, country factors also matter for the longrun interest rate, especially in Scandinavia.

Third, the equity market shows, perhaps unsurprisingly, much comovement across markets. In most countries the equity factor explains over $50 \%$ of the variance. Both the global and country factors only play a marginal role here. The high degree of stock market synchronization is well documented in the literature (See e.g. Longin and Solnik (1995) or Chinn and Forbes (2004)). With easy cross border access and highly liquid markets, prices can adjust quickly across all markets. 
Fourth, for housing prices the story is different and there are large differences on the importance of each factor across countries. The global factor plays a meaningful role in the United States, Canada, Finland, Spain, United Kingdom and New Zealand. When considering the global housing factor a large portion of the variance is explained in the United States, Finland, Spain, Sweden and United Kingdom. Consequently, housing prices in the United States, Finland, Spain, Sweden and United Kingdom are explained by global factors. Not surprisingly, Spain, U.K. and the U.S. show a large degree of housing price comovements since the burst of the housing market bubble in the United States. The country factor also plays an important role in some countries like Finland, Ireland, the Netherlands, Japan and New Zealand. However, some housing markets seem to behave idiosyncratically, where the factors do not explain much. This is the case in e.g. France, Italy and Norway.

\subsubsection{The Forecast Analysis}

The idea underlying extracting the constrained factors using Bayesian techniques is to represent large datasets using a small number of transmission channels allowing the transmission process. A little attention has been devoted to the forecasting power of these factors. When forming our idea about detecting contagion effects, we extract the best signals (factors) as to be the paths of the transmission process of a local U.S shock to other economies. We evaluate the forecast performance of the different common factors over the period going from 2006:Q3 until 2008:Q4.
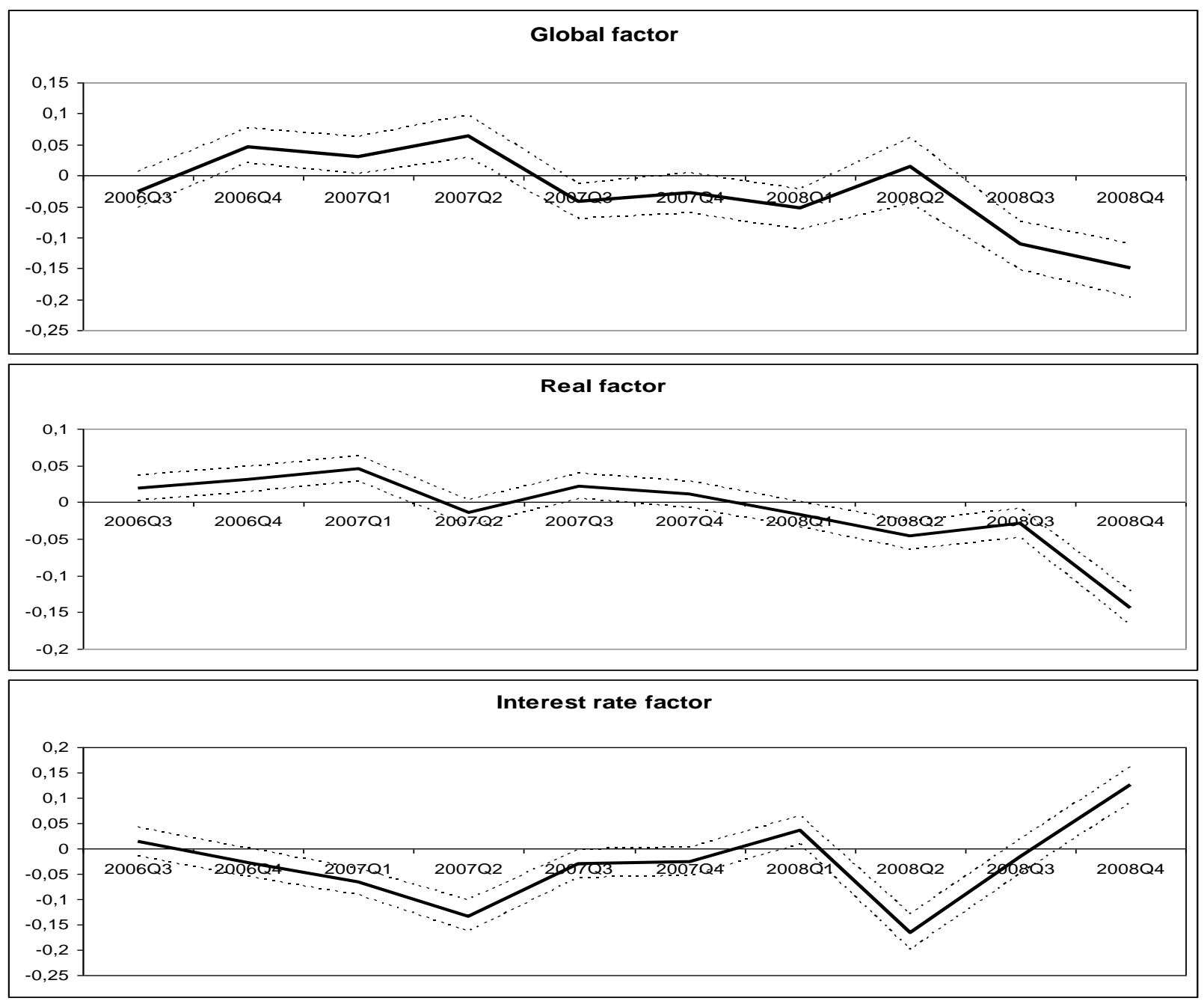

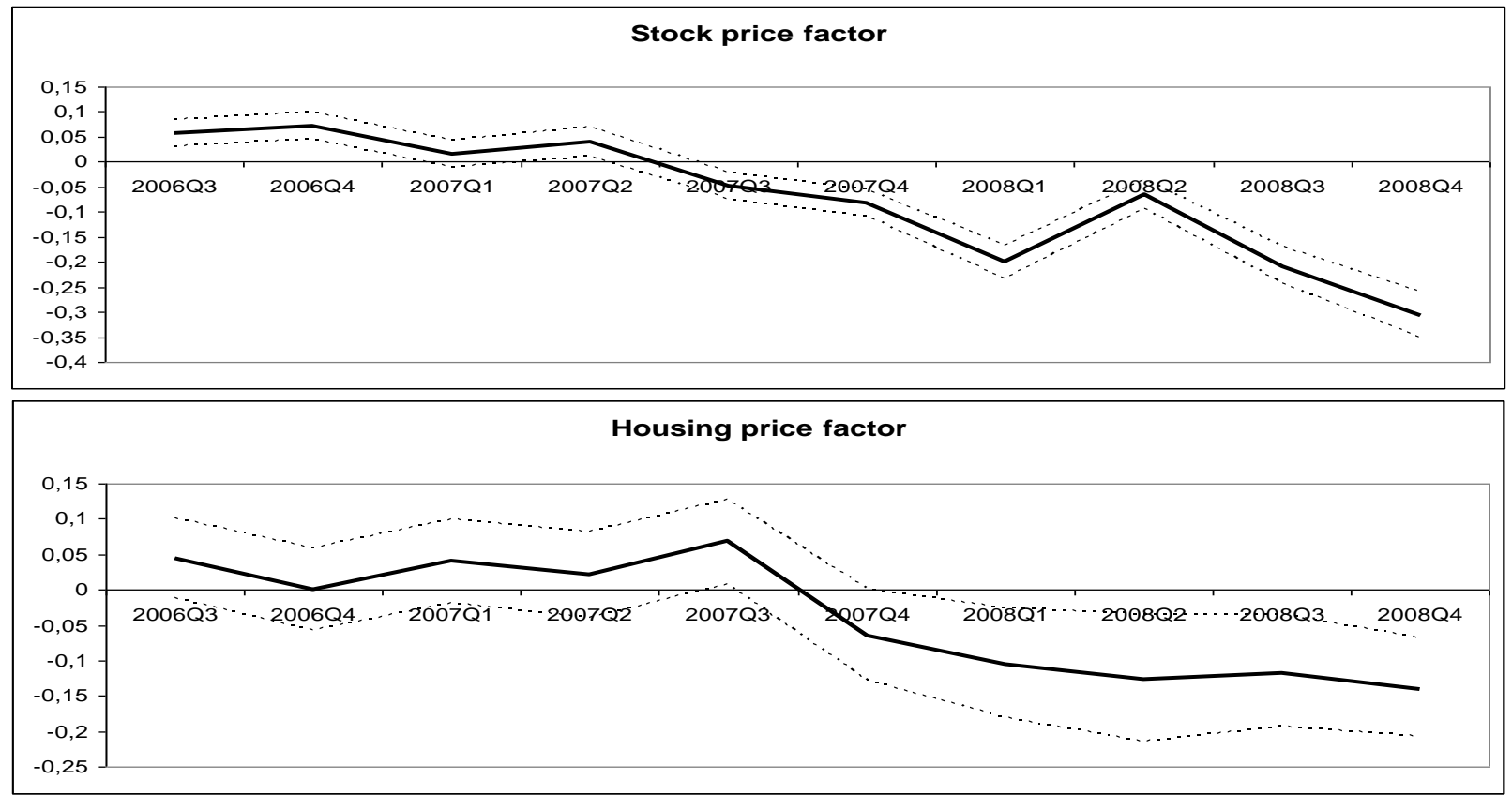

Figure 4: Forecast exercise on the dynamic factors 2006:Q3-2008:Q4

It seems that all the factors are impacted by the subprime and the financial crises of the U.S.

According to the world factor, two clear declines happened respectively in mid-2007 and mi-2008. Those are more probably reflecting the subprime and financial crises. For the global real activity factor, it appears that a decline happened in the first quarter of 2007. It maybe a delay between the beginning of the subprime crisis and its impact on the real activity of the OECD countries. Moreover, the most increase happened in the third quarter of 2008, the period of the Lehmans Brothers bankruptcy. The lowest point was noticed in the last quarter of 2008. Also, the interest rate factor seems to be very volatile. In fact, it appears that the rates were declining since mid-2006 until mid-2007, then increasing from that last date until the first quarter of 2008 to fall and achieve the lowest point in mid-2008 before increasing again. The global stock channel seems to be impacted in mid-2007 by the subprime crisis. For the housing price factor, it seems to be a continuous little decline since mid-2006 until the end of 2008.

We notice from the forecast exercise that the factors or transmission channels were impacted in a good sense by the subprime and then by the financial crisis.

In the next section, we will investigate the internationally transmission mechanisms, where shocks originating from the U.S. are transmitted to OECD countries through the transmission channels.

\subsubsection{Impulse Responses Analysis}

In this section, we augment a standard VAR model by including unobserved factors akin to Bernanke and al. (2005). These unobserved factors are chosen from the ones estimated in the previous section as previously explained. We will restrict our attention to the U.S. economy, which is a large economy and whose domestic shocks are likely to influence the common factors. Hence, the common factors are treated as endogenous in this model ${ }^{6}$. The vector of endogenous variables of the FAVAR is given by:

$Y_{t}=\left[\begin{array}{lllllll}H P I_{U S A, t} & F_{U S A, t}^{C} & F_{t}^{W} & F_{t}^{R E A L} & F_{t}^{I N T} & F_{t}^{E Q} & F_{t}^{H P I}\end{array}\right]$

${ }^{6}$ Treating these global variables as endogenous will be less realistic when a small economy, e.g. Ireland, is considered. 
which $H P I_{U S A, t}, F_{U S A, t}^{C}, F_{t}^{W}, F_{t}^{R E A L}, F_{t}^{I N T}, F_{t}^{E Q}$ and $F_{t}^{H P I}$ represent respectively, the growth rates of U.S. housing prices, the U.S. country factor, the real activity factor, the global interest rate factor, the stock market factor and the global housing factor.

Using this set-up the Akaike Information Criterion indicates that four lags of the endogenous variables need to be included in the model. The Hannan-Quinn Criterion and the Schwarz criterion indicate only two or one lag, respectively. Choosing four lags seems to be a natural choice since we are dealing with quarterly data. Moreover, further analysis shows that four lags are necessary to eliminate all residual serial correlation. One alternative is to allow an unrestricted estimation involving 6 endogenous variables. However, for efficiency reasons we choose to use a top-down approach with the Hannan-Quinn criterion to find possible coefficients which we can set to zero. The Lütkepohl and Doornik-Hansen tests for joint non-normality show signs of excess kurtosis in the innovations. There appear to be no problems concerning skewness. However, the joint non-normality tests reject normality. On the individual series level the Jarque-Bera test shows that normality at the individual series level is rejected only for the residuals of domestic US housing prices. There are no signs of residual serial correlation, which appears to be eliminated with the inclusion of four lags. In sum, the assumptions of normality and no autocorrelation appear to be satisfied for most individual series. However, we will estimate this restricted model using Feasible GLS. Moreover, we will use bootstrapped confidence bounds to conduct conservative conclusions in the impulse response analysis.

\subsubsection{A positive shock to U.S housing prices}

In the following section, we will investigate the emergence of a positive housing price shock originating in the United States mid-2006. This shock is a simulation of the subprime crisis. Such a crisis is likely to boost housing prices. Note that the analysis is symmetric and can be used to analyze housing price decreases as well.

Figure 5 shows the cumulative impulse response functions of a positive shock to United States real housing prices. The first graph shows the response of the U.S. country factor, the second of the housing price factor, the third of the real factor and the fourth of the global factor. The $90 \%$ confidence bounds are constructed using bootstrapped Hall studentized standard errors. This will make the confidence bounds more robust against possible nonnormalities.

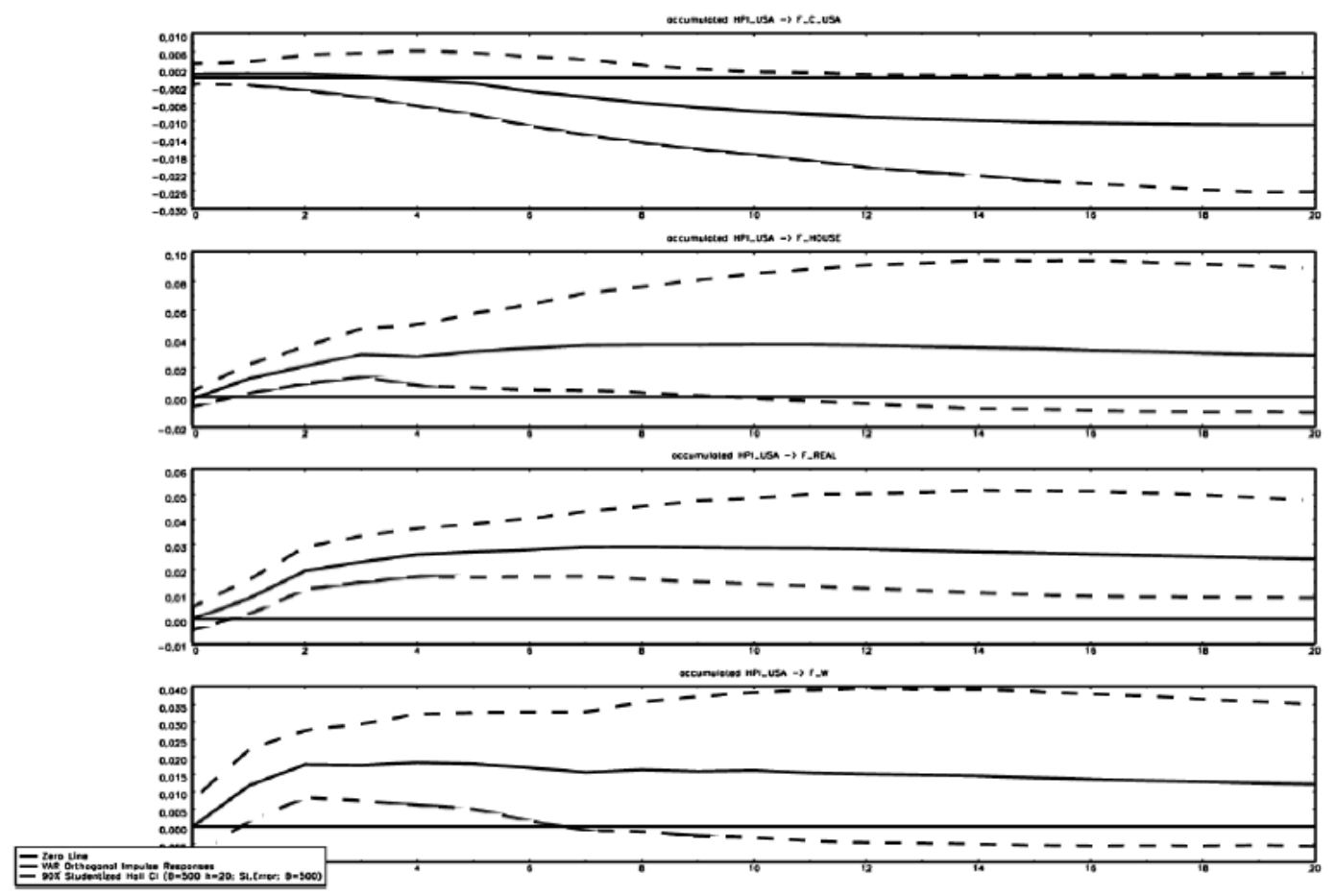

Figure 5: Impulse responses to a positive housing price shock, median and $90 \%$ confidence bounds Note: the dotted lines indicate the posterior coverage intervals corresponding to $90 \%$ confidence levels. 
The positive U.S. housing price shock has an unclear effect on the U.S. country factor. However, the other graphs show strong spillover effects to the global factors.

First, the increase in U.S. house prices results in a significant increase in the global house price factor. This implies that countries whose housing market has a positive loading on the housing factor will experience an increase in housing prices, ceteris paribus.

Second, the effects of the U.S. housing price shock are not restricted to only the housing market.

Instead, the world factor and real factor show a significant increase as well. This effect sheds light on the transmission channel of global GDP decreases. Since the real factor explains a large portion of global GDP developments, an increase in this real factor will result in increases in domestic GDP.

Table 2 : Factor loadings

\begin{tabular}{|c|c|c|c|c|c|c|c|c|c|c|c|c|c|c|c|c|c|}
\hline Factor & USA & CAN & FIN & FRA & DEU & IRL & ITA & NLD & ESP & DNK & NOR & SWE & CHE & GBR & AUS & JPN & NZL \\
\hline \multicolumn{18}{|c|}{ Gross Domestic Product } \\
\hline World & 0.04 & 0.05 & 0.02 & 0.01 & 0.00 & 0.02 & 0.01 & 0.01 & 0.02 & -0.02 & -0.03 & 0.03 & 0.02 & 0.05 & 0.03 & 0.02 & 0.02 \\
\hline Real & 0.05 & 0.08 & 0.12 & 0.09 & 0.09 & 0.19 & 0.10 & 0.08 & 0.11 & 0.14 & 0.17 & 0.21 & 0.08 & 0.08 & 0.10 & 0.03 & 0.08 \\
\hline Country & 0.14 & 0.19 & 0.17 & 0.01 & 0.16 & 0.4 & 0.03 & 0.07 & 0.11 & 0.04 & 0.03 & 0.01 & 0.05 & 0.05 & 0.01 & 0.24 & 0.10 \\
\hline \multicolumn{18}{|c|}{ Consumption } \\
\hline World & 0.03 & 0.04 & -0.02 & 0.01 & 0.00 & 0.00 & 0.01 & -0.01 & 0.02 & 0.02 & -0.01 & 0.01 & 0.01 & 0.02 & 0.02 & 0.01 & 0.06 \\
\hline Real & 0.05 & 0.05 & 0.07 & 0.07 & 0.04 & 0.15 & 0.11 & 0.06 & 0.10 & 0.20 & 0.11 & 0.17 & 0.04 & 0.08 & 0.06 & 0.00 & 0.04 \\
\hline Country & 0.09 & 0.11 & 0.07 & -0.01 & 0.11 & 0.14 & 0.00 & 0.04 & 0.04 & 0.04 & 0.02 & 0.00 & 0.03 & 0.05 & 0.01 & 0.17 & 0.13 \\
\hline \multicolumn{18}{|c|}{ Investment } \\
\hline World & 0.07 & 0.06 & -0.01 & 0.04 & 0.01 & 0.12 & 0.02 & 0.09 & 0.00 & -0.03 & 0.01 & 0.05 & 0.13 & 0.07 & 0.06 & 0.02 & 0.10 \\
\hline Real & 0.12 & 0.21 & 0.21 & 0.15 & 0.17 & 0.52 & 0.27 & 0.18 & 0.33 & 0.31 & 0.25 & 0.29 & 0.17 & 0.27 & 0.22 & 0.08 & 0.06 \\
\hline Country & 0.39 & 0.27 & 0.45 & 0.00 & 0.34 & 1.09 & 0.08 & 0.19 & 0.09 & 0.00 & -0.05 & 0.02 & 0.10 & 0.08 & 0.04 & 0.43 & 0.38 \\
\hline \multicolumn{18}{|c|}{ 3-Month Short Interest Rate } \\
\hline World & 0.73 & 0.28 & -0.23 & -0.21 & -1.38 & -0.35 & -1.51 & -0.52 & -0.68 & -0.29 & -0.92 & -0.04 & -0.49 & 0.13 & -0.65 & -1.12 & -0.52 \\
\hline Country & -2.08 & -2.77 & -0.91 & -2.56 & -2.52 & -1.22 & -2.11 & -3.00 & -0.47 & -0.85 & -0.80 & -2.75 & -2.77 & -1.64 & -0.73 & -0.94 & -2.94 \\
\hline Interest & 1.39 & -0.29 & 0.84 & -0.98 & 0.52 & 0.07 & 1.58 & 0.72 & -0.77 & -1.57 & -1.38 & 1.74 & 1.81 & -0.35 & 3.12 & 0.51 & -0.01 \\
\hline \multicolumn{18}{|c|}{ 10-Year Long Interest Rate } \\
\hline World & 2.87 & 1.90 & 0.15 & 0.29 & 0.30 & 0.50 & -0.66 & 0.27 & -0.17 & 1.18 & -0.10 & 1.63 & 0.86 & 1.42 & 0.61 & 1.27 & -0.44 \\
\hline Country & -2.76 & -3.18 & -2.37 & -3. & -3.07 & -3.15 & -2.62 & -3.3 & -1.8 & -3.04 & -2.18 & -3.00 & -2.12 & -2.80 & -2.21 & -1.51 & -0.89 \\
\hline Interest & 2.05 & -1.47 & 1.34 & -2.22 & 0.33 & 0.15 & 3.17 & 0.62 & -1.25 & -4.60 & -1.64 & 5.00 & 1.43 & -1.70 & 2.39 & 0.26 & 0.98 \\
\hline \multicolumn{18}{|c|}{ Stock Market Index } \\
\hline World & -0.08 & -0.02 & 0.54 & 0.20 & 0.24 & 0.34 & 0.27 & 0.15 & 0.18 & 0.37 & 0.72 & 0.28 & 0.02 & -0.06 & 0.13 & 0.29 & 0.17 \\
\hline Country & 0.61 & 0.58 & 0.83 & 0.76 & 0.83 & 0.84 & 0.77 & 0.77 & 0.77 & 0.54 & 0.78 & 0.95 & 0.74 & 0.61 & 0.58 & 0.53 & 0.55 \\
\hline Stock & -0.12 & 1.03 & -0.17 & 0.61 & 0.17 & 0.46 & -0.19 & 0.07 & 0.33 & 0.21 & 0.38 & -0.45 & -0.01 & 0.30 & -0.07 & 0.32 & -0.19 \\
\hline \multicolumn{18}{|c|}{ Housing Prices Index } \\
\hline World & 0.03 & 0.09 & 0.04 & 0.00 & 0.00 & 0.08 & 0.01 & -0.01 & 0.04 & 0.03 & 0.02 & 0.00 & 0.03 & 0.03 & 0.00 & 0.03 & 0.05 \\
\hline Housing & $\mathbf{0 . 0 3}$ & 0.07 & 0.07 & 0.02 & 0.00 & 0.09 & 0.01 & 0.02 & 0.04 & 0.07 & 0.09 & 0.13 & 0.07 & 0.08 & 0.07 & 0.02 & 0.01 \\
\hline Country & 0.00 & 0.26 & 0.19 & -0.02 & 0.04 & 0.51 & 0.01 & 0.07 & 0.10 & 0.12 & 0.04 & 0.02 & 0.02 & 0.06 & 0.01 & 0.05 & 0.07 \\
\hline
\end{tabular}

Note: The table reports the median of the loading estimates. Figures in bold indicate a loading significantly different from zero.

Table 2 displays the loadings on each factor for all variables. A bold number indicates that the loading is significantly different from zero at the $90 \%$ confidence level. The following countries will experience a significant increase in domestic housing prices as a result of the increase in the global housing factor: Finland, Denmark, Norway, Sweden, Switzerland, United Kingdom and Australia. However, note that Canada, Ireland and Denmark have a relatively large loading on the housing price factor, but due to larger confidence bounds, these loadings are not significantly different from zero. Fewer countries are significantly affected by the increase in the world factor.

One limitation of this FAVAR model is that is not able to capture the effect of the U.S. housing price shock on the respective country factor. We can infer spillover effects from the world factor to other sectors of the economy. For example, since the real factor increases significantly the real economy of all countries is affected by the shock to U.S. housing prices. Basically and from the results, only the Japanese economy would be rather isolated from the global real activity factor. In order to obtain more insight in the determinants of the housing factor, we perform a forecast error variance decomposition (FEVD). 
Table 3 reports the FEVDs of : 1) The global housing price factor and 2) U.S. domestic housing prices. The forecast horizon ranges from 1-20 quarters.

Table 3: Forecast variance error decomposition

\begin{tabular}{|c|c|c|c|c|c|c|}
\hline \multicolumn{7}{|c|}{ Global housing price factor } \\
\hline Forecast horizon & HPI_USA & F_C_USA & F_HOUSE & F_REAL_ & F_NT & F_WLD \\
\hline 1 & 0.00 & 0.00 & 1.00 & 0.00 & 0.00 & 0.00 \\
\hline 5 & 0.11 & 0.01 & 0.66 & 0.16 & 0.01 & 0.06 \\
\hline 10 & 0.08 & 0.04 & 0.62 & 0.21 & 0.01 & 0.05 \\
\hline 15 & 0.08 & 0.05 & 0.59 & 0.22 & 0.01 & 0.05 \\
\hline 20 & 0.08 & 0.06 & 0.59 & 0.22 & 0.01 & 0.05 \\
\hline \multicolumn{7}{|c|}{ U.S. housing price index } \\
\hline Forecast horizon & HPI_USA & F_C_USA & F_HOUSE & F_REAL & F_NT & F_WLD \\
\hline 1 & 1.00 & 0.00 & 0.00 & 0.00 & 0.00 & 0.00 \\
\hline 5 & 0.85 & 0.04 & 0.02 & 0.07 & 0.00 & 0.02 \\
\hline 10 & 0.84 & 0.05 & 0.02 & 0.07 & 0.00 & 0.02 \\
\hline 15 & 0.83 & 0.05 & 0.02 & 0.07 & 0.00 & 0.02 \\
\hline 20 & 0.82 & 0.05 & 0.03 & 0.07 & 0.00 & 0.02 \\
\hline
\end{tabular}

Note: The numbers in the table report fraction of the variance explained.

The variance decompositions in Table 3 show that U.S. housing price shocks appear to behave rather idiosyncratically. Even after 20 quarters, the variable itself explains over $80 \%$ of the shock. In contrast, the included variables explain more of the shocks on the global housing factor. For example, the real factor explains about $22 \%$ of the variance after 20 quarters and U.S. housing prices explain about $8 \%$.

\subsubsection{A positive shock to U.S short run interest rates}

According to the literature and to most economists, the subprime crisis was, at least, partly the U.S. Fed's fault. In fact, we simulate the subprime crisis in mid-2006 taking into account the policy of the Fed during 20052006 with large increases.

So in a second specification, we replace U.S. housing prices with the U.S. short run interest rate and study the effect of a positive shock to U.S. short run interest rates. The FAVAR model estimated is as follows:

$$
Y_{t}=\left[\begin{array}{lllllll}
I R S_{U S A, t} & F_{U S A, t}^{C} & F_{t}^{W} & F_{t}^{R E A L} & F_{t}^{I N T} & F_{t}^{E Q} & F_{t}^{H P I}
\end{array}\right]^{\prime}
$$

where IRS $S_{U S A, t}, F_{U S A, t}^{C}, F_{t}^{W}, F_{t}^{R E A L}, F_{t}^{I N T}, F_{t}^{E Q}$ and $F_{t}^{H P I}$ represent respectively, the growth short-term 3month American interest rate, the U.S. country factor, the world factor, the real activity factor, the interest rates factor, the stock market factor and the global housing factor. Again four lags are chosen and the specification tests do not reject the assumptions of normality and no residual serial correlations where found.

The impulse responses along with 90\% confidence bounds are reported in Figure 6.

First, the short interest rate shock significantly decreases the U.S. country factor. This indicates that general economic activity will decrease.

Second, the short interest rate shock has a large effect on common factors: for instance, the housing factor and the real activity one both decrease, after some delay. It is well-known that it takes several quarters before interest rate changes affect the real economy. In addition, the world factor is also significantly affected by shocks to interest rates.

In sum, both changes in U.S. interest rates and housing prices are significantly transmitted to international common factors. 


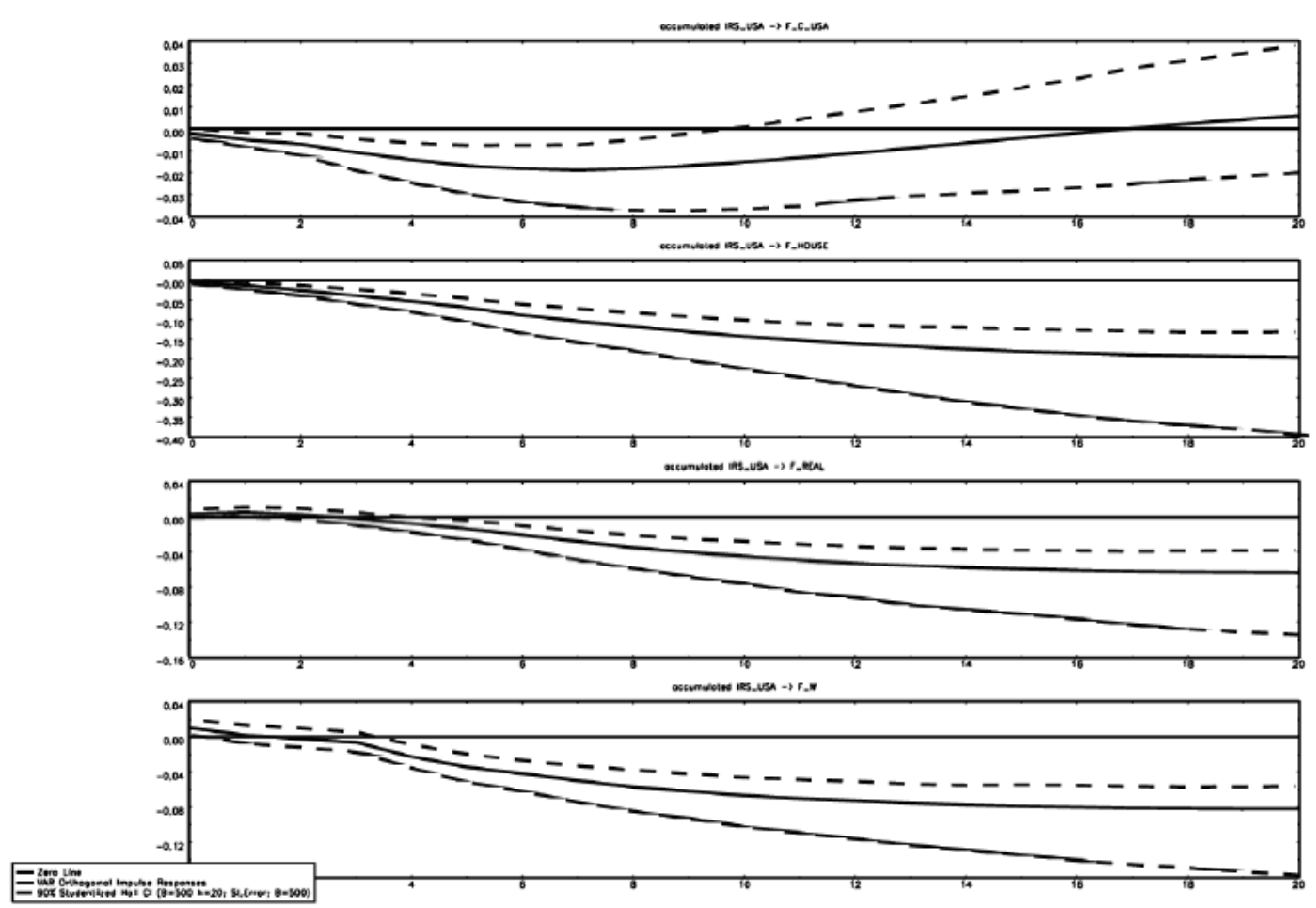

Figure 6: Impulse responses to a positive short run interest rate shock, median and $90 \%$ confidence bounds

Note: the dotted lines indicate the posterior coverage intervals corresponding to $90 \%$ confidence levels.

Using the loadings from Table 2 we can infer again the consequences on domestic housing markets across the world. As the results are qualitatively similar to those from the housing price shock we will not discuss these in detail again. However, what is interesting to observe is that the interest rate policy of the Fed during 2005-2006 with large increases has likely played an important role in housing price changes across the world.

In the above analysis we studied the effect of a shock to U.S. housing prices and a shock to U.S. short interest rates on the unobserved international factors. Hence, we need to infer what the effect of the U.S. is on those country specific factors.

So our analysis is interesting and can be made for several countries. In fact, the same analysis can be made for other countries even also can be extended with two-country FAVAR models. Specially, for most countries, their country factor plays an important role in domestic house price developments. For example, to study the effects of the U.S. housing price shock on Spanish housing markets, it will be possible to estimate the following model:

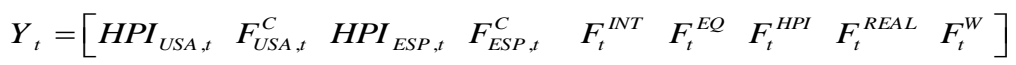

By using these types of FAVAR models we will have a clearer picture when analyzing the contagion effects of a housing price shock or interest rate shock originating in the United States on any other country. These models will be included in a new version of the paper.

Moreover, our analysis can be done in the case of a national country study. For instance, it might be important to allow for dynamic interaction between U.S. financial variables and other types of U.S. variables in the FAVARs.

\section{CONCLUSION}

In this paper we have focused on international transmission of shocks across housing markets around the world, in order to detect and measure contagion effects during the subprime crisis. 
We have characterized contagion as a pandemic process: it happens once a local shock originating from a national market spread out to other OECD markets.

We follow Bernanke et al. (2005) and use a two-step FAVAR approach by introducing a Bayesian framework.

First, constrained factors are extracted from a large database including housing prices and other economic indicators (GDP, consumption, investment, interest rates and stock index returns) for a panel of 17 countries observed over the period 1980:Q1-2006:Q2. The extracted factors are identified as world, country-specific and variable-type specific factors. They are orthogonal and estimated using Bayesian estimation methods.

Second, we have estimated FAVAR models for two specific shocks: 1) A U.S. housing price shock and 2) A U.S. short interest rate shock. These FAVAR models include both observed economic variables as well as unobserved factors chosen among the factors extracted in the first step.

We have shown that contagion can be observed:

1/ as local housing price shock originating from America is proved to affect the international common factors, which in turn impact significantly other local or international variables, according to a pandemic mechanism. In addition, there are spillovers to the rest of the economy as the world factor and the real activity one are affected as well.

2/ due to the FED's monetary policy. More particularly, we have examined whether the sharp increase in the interest rates decided by the FED after the low interest rates that were offered during 2003 and 2004 may have been the local shock starting the so-called subprime mortgage crisis, which has involved the generalized troubles observed in many housing markets, notably, USA, U.K and Spain and also stock markets and have more recently affected the activity of so many countries.

Our results show that the interest rate shock appears to play an important role in the spillover mechanism from the United States to the rest of the world.

Our main findings suggest that differences exist in the contagion effects. This implies that no generalizations can be made for OECD countries even for one of equal economic size and in the same geographic region.

We find that a large portion of the variance of OECD variables is explained by the common factors. This suggests that American shocks, which are able to impact the common factors, will be transmitted to some, but not all OECD countries. More precisely, Australia, the United Kingdom and Scandinavian countries appear to be most sensitive to global shocks. However, even though global developments play an important role in most OECD economies, a large part of the variance is still idiosyncratic.

Besides, the confidence bands for the housing factor are not tight enough. It may indicate that it may be necessary to consider several house price factors, because the dynamics of countries housing markets are not highly synchronized. In our future work, we will formally compare models with more than one housing factor and also a model with no housing factor with their baseline model and then re-decide upon their baseline model based on this exercise. We will follow $\mathrm{Ng}$ and Moench (2011) by using a hierarchical factor analysis of the OECD housing markets dynamics.

\section{AUTHOR INFORMATION}

Olfa KAABIA, University of Paris Ouest Nanterre la Defense, France. E-mail: olfa.kaabia@u-paris10.fr (Corresponding author)

Ilyes ABID, University of Paris Ouest Nanterre la Defense, France. E-mail: ilyes.abid@u-paris10.fr 


\section{REFERENCES}

1. $\quad$ Altug, S. (1989). "Time-to-Build and Aggregate Fluctuations: Some New Evidence", International Economic Review, 30, 889-920.

2. Bai, J. (2003). "Inferential Theory for Factor Models of Large Dimensions", Econometrica, Econometric Society, vol. 71(1), pages 135-171.

3. Bai, J. and Ng S. (2008). "Extremum Estimation when the Predictors are Estimated from Large Panels", Annals of Economics and Finance, Society for AEF, vol. 9(2), pages 201-222.

4. Beltratti, A. and Morana, C. (2010). "International House Prices, and Macroeconomic Fluctuations", Journal of Banking and Finance. Vol. 34, pages 535-545.

5. Bernanke, B., Boivin, J. and Eliasz, P. (2005). "Measuring the Effects of Monetary Policy: a Factor Augmented Vector Autoregressive (FAVAR) Approach", Quarterly Journal of Economics, February 2005.

6. Case K., Shiller R., and Quigley J. (2005). "Comparing wealth effects: the stock market versus the housing market". Advances in Macroeconomics, vol. 5(1), pages 1-32.

7. Chinn, M.D., Forbes, K.J. (2004). "A Decomposition of Global Linkages in Financial Markets Over Time". The Review of Economics and Statistics, vol. 86(3), pages 705-722.

8. Del Negro, M. and Otrok, C. (2007). "99 Luftballons: Monetary Policy and the Housing Price Boom across US States", Journal of Monetary Economics, vol. 54, pages 1962-1985.

9. $\quad$ Eickmeier, S. (2007). "Business Cycle Transmission from the US to Germany-A Structural Factor Approach", European Economic Review, vol. 51, pages 521-551.

10. Giuliodori, M. (2005). "The Role Of House Prices In The Monetary Transmission Mechanism Across European Countries," Scottish Journal of Political Economy, Scottish Economic Society, vol. 52(4), pages 519-543.

11. Goodhart, C. and Hofmann, B. (2008). "Housing Prices, Money, Credit and Macro economy", Oxford Review of Economic Policy, vol. 24(1), pages 180-205.

12. Iacoviello, M. and Neri, S. (2010). "Housing Market Spillovers: Evidence from an Estimated DSGE Model", American Economic Journal of Macroeconomics, American Economic Association, vol. 2(2), pages 125-64.

13. Kaminsky, G. and Reinhart, C. (2000). "On Crises, Contagion, and Confusion", Journal of International Economics, vol. 51(1), pages 145-168.

14. Kaminsky, G. and Reinhart, C. (2000). "Notes on contagion", MPRA Paper 24569, University Library of Munich, Germany.

15. Kose, A., Otrok, C. and Whiteman, C. (2003). "International Business Cycles: World, Region, and CountrySpecific Factors," American Economic Review, Vol. 93 (Sept), pp.1216-39.

16. Lettau, M. and Ludvigson, S. (2001). "Consumption, Aggregate Wealth, and Stock Returns", The Journal of Finance, LVI(3), pages 815-849.

17. Lettau, M. and Ludvigson, S. (2004). "Understanding Trend and Cycle in Asset Values: Reevaluating the Wealth Effect on Consumption," American Economic Review, American Economic Association, vol. 94(1), pages 276299, March.

18. Longin, F., Solnik, B. (1995). "Is the Correlation in International Equity Returns Constant: 1960-1990?" Journal of International Money and Finance, vol. 14(1), pages 3-26.

19. Ng S. and Moench E. (2011). "A hierarchical factor analysis of U.S. housing market dynamics," Econometrics Journal, Royal Economic Society, vol. 14(1), pages C1-C24, February.

20. Otrok, C. and Terrones, M. (2004). "The Global Housing Price Boom", IMF, World Economic Outlook, September.

21. Otrok, C., and Whiteman, C. (1998), "Bayesian Leading Indicators: Measuring and Predicting Economic Conditions in Iowa", International Economic Review, Vol. 39(4), pp. 997-1014.

22. Sargent, T. J. (1989). "Two Models of Measurements and the Investment Accelerator", the Journal of Political Economy, vol. 97, pages 251-287.

23. Stock, J. H. and Watson, M. W. (2003), "Understanding Changes in International Business Cycle Dynamics", NBER Working Papers 9859, National Bureau of Economic Research, Inc.

24. Stock, J. H. and Watson, M. W. (2005), "Implications of Dynamic Factor Models for VAR Analysis", NBER, Working Paper, http://www.nber.org/papers/w11467

25. Tanner, Martin A. and Wong, Wing H. (1987), "The Calculation of Posterior Distributions by Data Augmentation", Journal of the American Statistical Association, Vol. 82, N. 398, pp. 528-540.

26. Vansteenkiste, I. and Hiebert, P. (2009), "Do house price developments spill over across euro area countries: evidence from a Global VAR", European Central Bank, Working Paper, 1026.money. 